Natural Hazards and Earth System Sciences (2001) 1: 33-36

(C) European Geophysical Society 2001

Natural Hazards and Earth System Sciences

\title{
A precursory ULF signature for the Chi-Chi earthquake in Taiwan
}

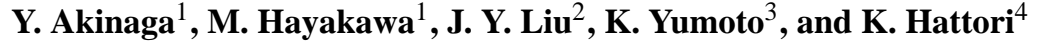 \\ ${ }^{1}$ Dept. of Electronic Engineering, The University of Electro-Communications, 1-5-1 Chofugaoka, Chofu Tokyo 182-8585, \\ Japan \\ ${ }^{2}$ Institute of Space Science, National Central University, Chung-Li 320, Taiwan \\ ${ }^{3}$ Dept. of Earth and Planetary Sciences, Kyushu University, 33 Hakozaki Fukuoka 812-8581, Japan \\ ${ }^{4}$ Marine Biosystems Research Center, Chiba University, 1-33 Yayoi, Inage Chiba 263-8522, Japan
}

Received: 10 May 2001 - Accepted: 23 July 2001

\begin{abstract}
ULF emission data at Lunping (epicentral distance, $120 \mathrm{~km}$ ) have been analysed for the Chi-chi earthquake (with magnitude 7.6 and depth of $11 \mathrm{~km}$ ) in Taiwan which occurred on 21 September 1999. Simple intensity analyses have not yielded any significant results but we have found, based on the analysis of polarization (the ratio of vertical magnetic field component $Z$ to the horizontal component $G$ ), that the polarization $(Z / G)$ showed a significant enhancement for two months before the earthquake. This kind of temporal evolution of polarization seems to be very similar to previous results, so that it is highly likely that this phenomenon may be associated with the Chi-Chi earthquake. Also, the comparison of the results of polarization analyses, by changing the signal threshold, has given us an approximate intensity of the seismogenic emission of the order of the monthly mean value.
\end{abstract}

\section{Introduction}

Based on subsurface measurements, much evidence has been accumulated on the presence of electromagnetic phenomena associated with earthquakes since the pioneering paper by Gokhberg et al. (1982) and Hayakawa and Fujinawa (1994), and references therein. In addition to these subsurface measurements, radio sounding measurements, by means of radio transmitters at different frequency ranges, have enabled us to detect the seismo-atmospheric and -ionospheric phenomena (Hayakawa, 1999 and references therein).

In the present paper we are interested in one of the most promising frequency ranges, ULF (Ultra-low-frequency; frequency $(0.005-10 \mathrm{~Hz}))$, in the passive measurement of seismo-electromagnetics, because previous investigations

Correspondence to: M. Hayakawa

(hayakawa@ aurora.ee.uec.ac.jp) have suggested the ULF as a prospective band for the search for earthquake precursory signatures (Kopytenko et al., 1990; Fraser-Smith et al., 1990; Molchanov et al., 1992; Hayakawa et al., 1996; Kawata et al., 1998; Hayakawa et al., 1999, 2000; Vallianatos and Tzanis, 1999). We will focus on the ULF emissions for the large Chi-Chi earthquake in Taiwan which occurred in September 1999.

2 ULF magnetic field measurements and the earthquake analyzed

A large earthquake (with magnitude 7.6 and with depth of $11 \mathrm{~km}$ ) took place in Taiwan at 01:47 LT (Local Time) on 21 September 1999; and the geographic coordinates of its epicenter are $\left(23.82^{\circ} \mathrm{N}, 120.89^{\circ} \mathrm{E}\right)$. This earthquake is named "Chi-Chi" earthquake after the name of the city at the epicenter. Figure 1 illustrates the epicenter of the earthquake and our ULF observing station.

It is very fortunate that there is a ULF magnetic observatory at Lunping (see Fig. 1), where the ULF magnetic fields are measured by three ring-core-type fluxgate magnetometers, $H$ (NS component), $D$ (EW component), and $Z$ (vertical component), and ULF data are digitized at $1 \mathrm{~s} \mathrm{sam-}$ pling rate, which limits the upper analyzable frequency to be $0.4 \mathrm{~Hz}$ (Yumoto et al., 1992). The data used in this paper cover the period from 1 September 1998 to 16 October 1999; but the ULF data after the earthquake are missing due to the troubles with measuring system. The epicentral distance is $120 \mathrm{~km}$ as in Fig. 1. Judging by the observational results for previous earthquakes (Spitak, Loma Prieta, Guam and Biak earthquakes) (Kopytenko et al., 1990; Fraser-Smith et al., 1990; Hayakawa et al., 1996, 2000) and also our theoretical estimation (Molchanov et al., 1995), the epicentral distance seems to be too long to detect any ULF signature; but 


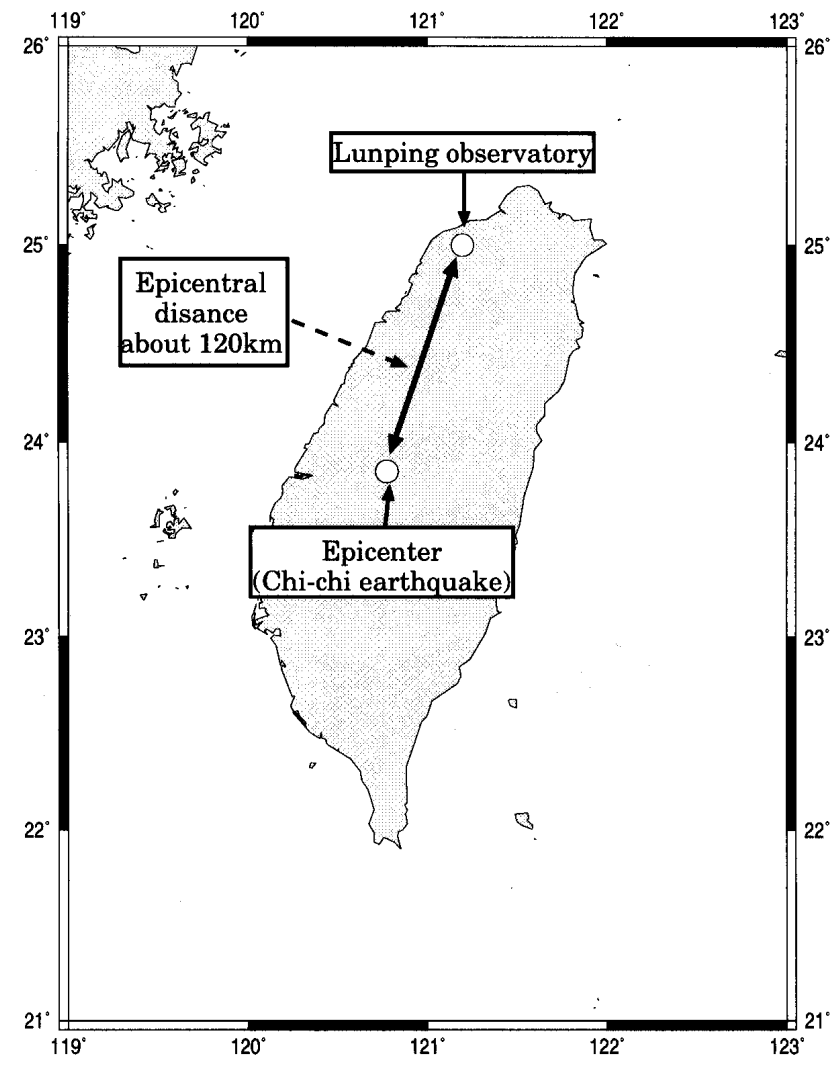

Fig. 1. Relative location of the ULF observing station (Lunping) with the epicenter of Chi-Chi earthquake.

its magnitude is large, so that we can try to find out whether there exists any ULF signature for this Chi-Chi earthquake.

\section{Data analysis and results}

As in the paper by Hayakawa et al. (1996), we have used the data during midnight period of $4 \mathrm{~h}$, from $\mathrm{LT}=00-04 \mathrm{~h}$, because the variability of the data at night is known to be smaller than at daytime (Saito, 1969). In our analysis of ULF data at Taiwan, we have encountered a lot of impulsive noises. One simple reason for this is that the observatory is located very close $(\sim 10 \mathrm{~km})$ to the industrialized city, Taipei. When we perform the analysis for the original data, including these impulsive noises, we are afraid that the results are misleading. So that, we have performed the following preliminary signal processing; (1) pulse noise filter, and (2) low-pass filter. After having looked at all of these pulses, we found that these pulses are very similar to each other; so the characteristics of the pulse filter are chosen as follows. The algorithm of our pulse filter is such that when the magnetic field at a particular time increases by " $b$ " nT during the successive time period of " $a$ " points (one point $=1 \mathrm{~s}$ ), we regard this as a pulse. We regard the end of this pulse at the points " $(c-a)$ " from the beginning, and then we remove this pulse by linearly connecting the initial and final points. By looking at the observed pulses in the data, we have tentatively chosen these parameters $(a=1, b=20$, and $c=10)$. By imposing a pulse filter with these parameters, we confirmed that this noise rejection is working well. Then we applied the low-pass filter to the data and the upper cutoff frequency is $0.5 \mathrm{~Hz}$.

Here, we have assumed that such impulsive noises are not natural but artificial but we are not sure whether they are really artificial. We have to study the characteristics of such impulsive noises in future but in this paper we analyze only the background ULF temporal evolution.

The waveforms of three magnetic field components during each interval of 30 min were subjected to an FFT analysis; the data for one day consists of 8 frequency spectra during each 30-min interval. The frequency spectrum of the magnetic field intensity for each 30-min interval is compared with the average value $(m)$ and the standard deviation $(s)$ over the whole period.

Looking at the behaviour at different frequencies, we conclude that some significant effects are seen at frequencies close to $0.01 \mathrm{~Hz}$ (period $=100 \mathrm{~s}$ ), which is already known to be characteristic for many seismo-ULF emissions (FraserSmith et al., 1990; Kopytenko et al., 1990; Hayakawa et al., 1999, 2000).

After the FFT analysis, we have plotted the temporal evolution of three magnetic field components $(H, D, Z)$ and the total horizontal magnetic field components $(G)$ at different frequencies. Even at the interesting frequency of $0.01 \mathrm{~Hz}$, such simple plots of each component have not exhibited any noticeable changes associated with the earthquake. A few possible signal processing have been proposed to find any significant ULF signature (i.e. polarization analysis (Hayakawa et al., 1996) and fractal analysis (Hayakawa et al., 1999; 2000)). In this paper, we use the polarization analysis for the ULF data in Taiwan. Figure 2 illustrates the temporal evolution of $Z / G$ at frequencies $(0.007 \mathrm{~Hz}-0.013 \mathrm{~Hz})$ during the whole period, where $Z$ is the vertical component of the magnetic field and $G$ is the total horizontal magnetic field component, $G=\sqrt{D^{2}+H^{2}}$. The thin line exhibiting sharp variations is the original result, and the full line is the running average over 5 days. It is seen from this curve that the polarization, $Z / G$, shows a significant enhancement for about two months before the quake and the value itself remained at a relatively high value until the quake. This change seems to be recognizable and significant by looking at the polarization behaviour during the whole period.

Figure 3 illustrates another representation of the temporal evolution of the polarization $(Z / G)$ at the same frequency $(0.007 \mathrm{~Hz} \sim 0.013 \mathrm{~Hz})$. In this figure we impose the following criterion: For example, in the top panel of the figure we impose the threshold in intensity $(m+s)$, where $m$ is the mean value during \pm 15 days for each day (total 31 days) and $s$ is the standard deviation during the same period as the mean, to the observed intensity which means that when the signal intensity ( $Z$ or $G$ ) exceeds its corresponding threshold (in this case, $m+s$ ), we estimate the ratio of those intensities (or polarization). This means that we take only the periods in which both $Z$ and $G$ are strong enough (exceeding $m+s$ ) 


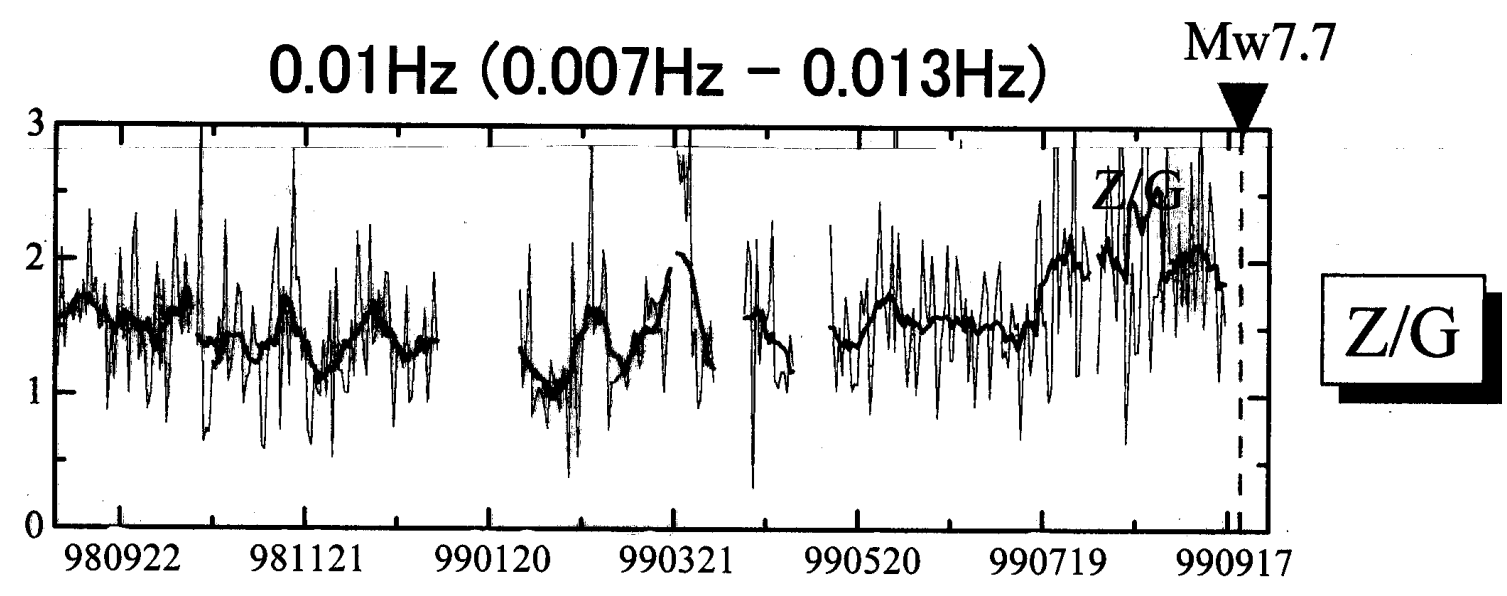

Fig. 2. Temporal evolution of the polarization $(Z / G)$ at a frequency of $0.007 \mathrm{~Hz}-0.013 \mathrm{~Hz}$ during the whole analyzed period. A significant enhancement in the polarization is seen for two months before the quake.

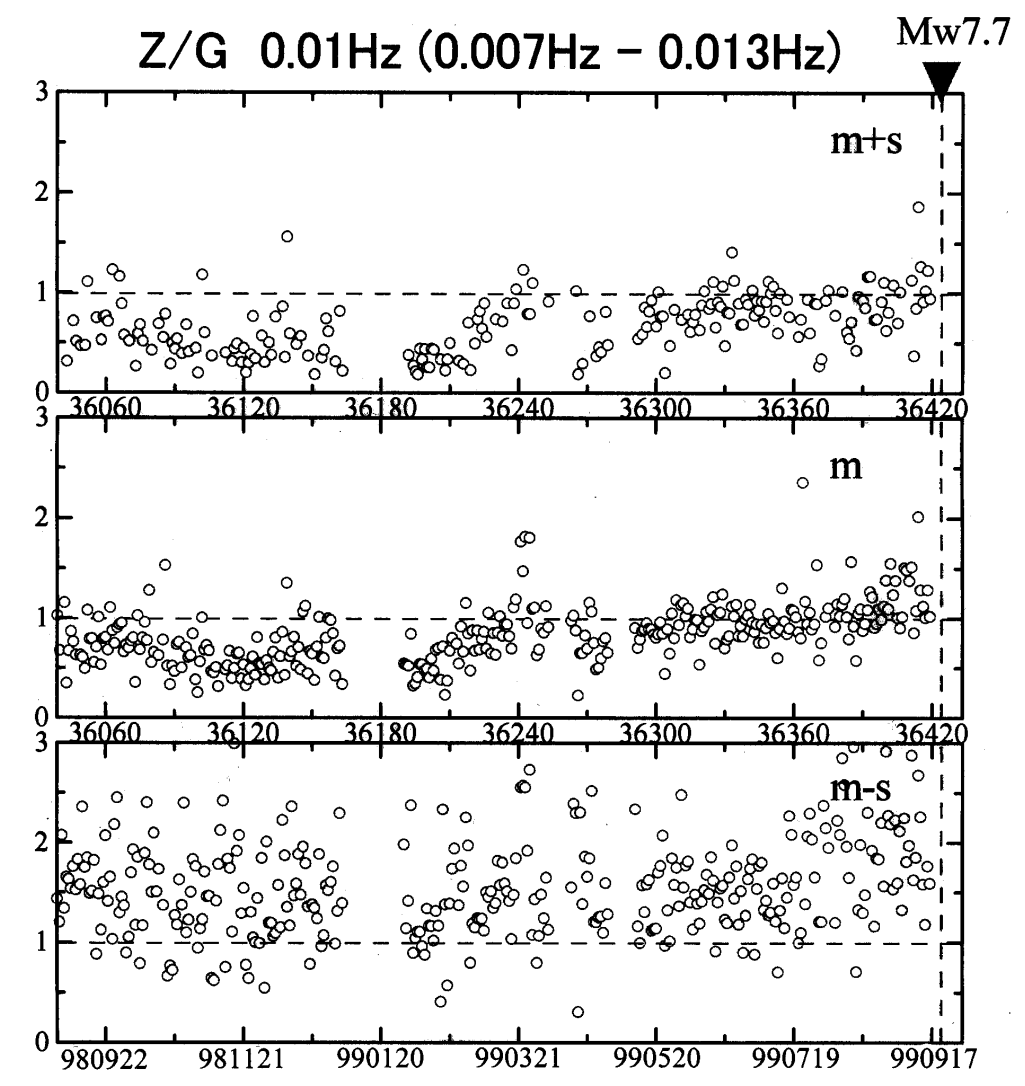

Fig. 3. Effect of changing the threshold on intensity on the temporal evolution of polarization $(Z / G)$ at the same frequency in Fig. 2. The threshold in the top panel is $m+s$ ( $m$ : mean and $s$; standard deviation), $m$ for the middle panel and $m-s$ for the bottom panel.

(i.e. strong signal to noise ratio). The second panel refers to the case of threshold of $m$, and the bottom panel, the threshold of $m-s$. By changing the threshold in intensity, we can infer the signal intensity of the observed seismogenic ULF emission. We have to comment here that this kind of signal processing has not been performed in obtaining Fig. 2, and this means that Fig. 2 is less reliable than Fig. 3 because Fig. 2 may include the result with low signal to noise ratio.
When we look at the top panel (threshold $=m+s$ ) in Fig. 3, the occurrence frequency of the polarization $(Z / G)$ exceeding unity, seems to remain at a high value for two months before the quake as already seen in Fig. 2. When the threshold is decreased down to $m$, the increases in polarization for two months before the quake is more easily recognizable than in the top panel, while it becomes rather difficult for us to understand what is happening in the polarization in the bottom 
panel with the threshold of $m-s$. A comparison of these figures may suggest that the intensity of the observed seismogenic emission is of the order of $m$.

\section{Conclusion}

The epicentral distance in the present case is $120 \mathrm{~km}$, so that we were afraid that we could not detect any ULF signature for the Chi-Chi earthquake in Taiwan. However, probably due to the big magnitude of the earthquake $(M=7.6)$, we could find out a convincing ULF precursory signature for this earthquake. The most characteristic frequency of the observed seismo-ULF emissions is found to be just around $0.01 \mathrm{~Hz}$ (period $=100 \mathrm{~s}$ ), which is consistent with all of the previous results (Spitak (Kopytenko et al., 1990); Loma Prieta (Fraser-Smith et al., 1992); Guam (Hayakawa et al., 1996); and Biak (Hayakawa et al., 2000) earthquakes). The analysis of polarization at this characteristic frequency has shown that the polarization increased significantly for two months before the quake. Unfortunately, we have no data just after the quake so we cannot say anything about the ULF emissions after the quake. This finding, on the significant change in polarization for the Chi-Chi earthquake and its temporal evolution, is very similar to our previous case studies (like Guam (Hayakawa et al., 1996) and Biak (Hayakawa et al., 2000) earthquakes) so that this phenomenon is highly likely to be a precursor to the Chi-Chi earthquake. Also, we can infer that the observed seismo-ULF emission has intensity of the order of the monthly mean value $(m)$ as inferred from Fig. 3. As for the generation mechanism of these seismogenic ULF emissions, we suggest the microfracturing model by Molchanov and Hayakawa (1995), which has been extended by several workers including Surkov (1999) and Vallianatos and Tzanis (1998).

\section{References}

Fraser-Smith, A. C., Bernardi, A., McGill, P. R., Ladd, M. E., Helliwell, R. A., and Villard, Jr., O. G.: Low-frequency magnetic field measurements near the epicenter of the Ms 7.1 Loma Prieta earthquake, Geophys. Res. Lett., 17, 1465-1468, 1990.

Gokhberg, M. B., Morgounov, V. A., Yoshino, T., and Tomizawa, I.: Experimental measurement of electromagnetic emissions possibly related to earthquakes in Japan, J. Geophys. Res., 87, 78247828, 1982.

Hayakawa, M.: (Ed), Atmospheric and Ionospheeric Electromagnetic Phenomena Associated with Earthquakes, Terra Sci. Pub. Co., Tokyo, pp. 996, 1999.

Hayakawa, M. and Fujinawa, Y.: (Eds), Electromagnetic Phenom- ena Related to Earthquake Prediction, Terra Sci. Pub. Co., Tokyo, pp. 677, 1994.

Hayakawa, M., Ito, T., and Smirnova, N.: Fractal analysis of geomagnetic ULF data associated with the Guam earthquake on 8 August 1993, Geophys. Res. Lett., 26, 2797-2800, 1999.

Hayakawa, M., Kawate, R., Molchanov, O. A., and Yumoto, K.: Results of ultra-low-frequency magnetic field measurements during the Guam earthquake of 8 August 1933, Geophys. Res. Lett., 23, 241-244, 1996.

Hayakawa, M., Itoh, T., Hattori, K., and Yumoto, K.: ULF electromagnetic precursors for an earthquake in Biak, Indonesia on 17 February 1966, Geophys. Ress. Lett., 27, 1531-1534, 2000.

Kawate, R., Molchanov, O. A., and Hayakawa, M.: Ultra-lowfrequency magnetic fields during the Guam earthquake of $8 \mathrm{Au}-$ gust 1993 and their interpretation, Phys. Earth Planet Inter., 105, 229-238, 1998.

Kopytenko, Yu. A., Matiashvili, T. G., Voronov, P. M., Kopytenko, E. A., and Molchanov, O. A.: Ultra low frequency emission associated with Spitak earthquake and following aftershock activity using geomagnetic pulsation data at observatories Dusheti and Vardziya, Preprint of IZMIRAN, N3(888), Moscow, January, 1990.

Molchanov, O. A. and Hayakawa, M.: Generation of ULF electromagnetic emissions by microfracturing, Geohpys. Res. Lett., 22, 3091-3094, 1995.

Molchanov, O. A., Kopytenko, Yu. A., Voronov, P. M., Kopytenko, E. A., Matiashvili, T. G., Fraser-Smith, A. C., and Bernardi, A.: Results of ULF magnetic field measurements near the epicenters of the Spitak $(M s=6.9)$ and Loma Prieta $(M s=7.1)$ earthquakes: Comparative analysis, Geophys. Res. Lett., 19, 14951498, 1992.

Molchanov, O. A., Hayakawa, M., and Rafalsky, V. A.: Penetration characteristics of electromagnetic emissions from an underground seismic source into the atmosphere, ionosphere and magnetosphere, J. Geophys. Res., 100, 1697-1712, 1995.

Saito, T.: Geomagnetic pulsations, Space Sci. Rev., 10, 319-412, 1969.

Surkov, V.: ULF electromagnetic perturbations resulting from the fracture and dilatancy in the earthquake preparation zone, in: Atmospheric and Ionospheric Electromagnetic Phenomena Associated with Earthquakes, (Ed) Hayakawa, M., Terra Sci. Pub. Co., Tokyo, 371-382, 1999.

Vallianatos, F. and Tzanis, A.: A model for the generation of precursory electric and magnetic fields associated with the deformation rate of the earthquake focus, in: Atmospheric and Ionospheric Electromagnetic Phenomena Associated with Earthquakes, (Ed) Hayakawa, M., Terra Sci. Pub. Co., Tokyo, 287-305, 1999.

Yumoto, K., Tanaka, Y., Oguti, T., Shiokawa, K., Yoshimura, U., Isono, A., Fraser, B. J., Menk, F. W., Lynn, J. W., and Seto, M.: $210^{\circ} \mathrm{MM}$ magnetic obsevation group, Globally coordinated magnetic observations along 210 magnetic meridian during STEP period, 1: Preliminary results of low-latitude Pc3's, J. Geomag. Geoelectr., 44, 261-276, 1992. 